\title{
Effect of Slotted holes on performance of Disc Brake
}

\author{
Ch.Indira Priyadarsini \\ †Mechanical engineering Department, Chaitanya Bharathi Institute of Technology, Hyderabad, India \\ Received 10 Nov 2017, Accepted 10 Jan 2018, Available online 12 Jan 2018, Vol.8, No.1 (Jan/Feb 2018)
}

\begin{abstract}
The disc brake is a device for slowing or stopping the rotation of a wheel. Repetitive braking of the vehicle leads to heat generation during each braking event. Transient Thermal Analysis of the Rotor Disc of Disk Brake is aimed at evaluating the performance of disc brake rotor of a car under severe braking conditions and there by assist in disc rotor design and analysis. Disc brake model and analysis is done using ANSYS workbench 16.0. The main purpose of this study is to analysis the thermo mechanical behaviour of the dry contact of the brake disc during the braking phase. The coupled thermal-structural analysis is used to determine the thermal stresses and to calculate the Heat fluxes in $x-y-z$ planes. This is established Slotted type and analysis is done by taking two different components such as Cast Iron and Stainless Steel and comparing which material is best suited for making of a disc bra ke.
\end{abstract}

Keywords: Disc brake, Thermal analysis, ANSYS workbench, Structural analysis.

\section{Introduction}

A disk brake consists of a cast iron disk bolted to the wheel hub and a stationary housing called caliper. The caliper is connected to some stationary part of the vehicle like the axle casing or the stub axle as is cast in two parts each part containing a piston. In between each piston and the disk there is a friction pad held in position by retaining pins, spring plates etc. passages are drilled in the caliper for the fluid to enter or leave each housing. The passages are also connected to another one for bleeding. Each cylinder contains rubber-sealing ring between the cylinder and piston. Disk brake types: 1 . Drilled type 2. Drilled and slotted. 3. Disk with internally slotted.

Nevertheless, they are certain issues arising in the disc brakes while braking. Some of the issues which generally occur while braking are: NVH and Thermal issues.

\section{NVH Issues}

Noise, vibration and harshness are complex issues that involve the entire system of components from the brake system. Ongoing investigations in the industry have identified several initiating factors relating to the brake elements themselves which can be grouped into the following sections:

1.Brake disc hot spots which typically result in thermal judder.

2. Uneven rotor thickness wear and rotor thickness variation.

${ }^{*}$ Corresponding author's ORCID ID: 0000-0002-4111-0017 DOI: https://doi.org/10.14741/ijcet.v8i01.10889

\section{Rotor deflection and oscillation.}

\section{Thermal management issues}

1. Uneven heating of brake rotors can temporarily cause, or increase, thickness variation, and sometimes can produce a primary thermal buckling that warps the rotor.

2. Uneven rotor cooling in the case of a vehicle parked immediately following strenuous braking activity can cause the area of rotor under the brake pads to cool more slowly than the portion of the rotor open to the atmosphere, resulting in uneven thermal stresses in the rotor and leading to pad imprinting, residual internal stresses and material failure.

\section{Objective}

The main objectives in this work are:

1. To perform the thermal analysis on the disc brakes and to determine the thermal stresses, and to calculate the corresponding Heat flux of the disc brake by taking boundary conditions.

2. Evaluating the performance of individual disc brake under certain braking conditions.

3. Choosing the best possible material from the given materials under the required conditions.

\section{Literature}

Investigations performed to know the temperature fields of the solid disc brake during short, emergency braking. Transient thermal analysis of disc brakes in 
single brake application was performed. To obtain the numerical simulation parabolic heat conduction equation for two dimensional model was used. The results show that both evolution of rotating speed of disc and contact pressure with specific material properties intensely. In basic working operation, a disc or drum brake system has to reduce wheel speed when a driver desires vehicle deceleration. The kinetic energy generated by a vehicle in terms of wheel speed is converted into heat energy due to the application of the brake system. The friction force between disc/drum and brake pad/brake shoe applies friction torque to the wheel in the opposite direction of the car's movement. This result in the reduction of vehicle speed and heat energy occurring in the brake disc/drum causes a temperature increment in the disc/drum swept area during the brake application. This physical action of the brake disc/drum causes heat conduction to the adjacent braking system components (S. Lakkam et al, 2013), (K. Lee, 1999). The inconsistent dissipation of heat inside the brake disc could cause deformation of the disc. Even worst, the disc deformation could also cause friction loss and consequently led to brake fade (G. Cueva et al, 2013). Furthermore, high temperatures of the brake disc could cause cracking in the brake disc material due to high thermal stresses. On top of that these factors also cause vibration (F. Bergman et al, 1999, A. Papinniemia et al, 2002). It is become common in the brake research community to fully utilize finite element approach in order to identify and predict disc/drum brake structural performance. For instance, the physical shape of vehicle brake discs play a significant role in determining the temperature characteristics including the overall brake efficiency (S. Koetniyom, 2003).

There is a link interaction between mechanical and thermal effects with disc movements and heat caused by frictions. They concluded that, from finite element analysis, temperatures on the disc surface changed at each point over the period, which indicates inconsistent dissipation and temperature differences in each side of the disc. Hence, inconsistent contact between disc and pad could affect material deformation (Kamnerdtong etal, 2005). The finite element Sofware ANSYS study for the thermal behaviour of the dry contact between the discs of brake pads at the time of braking phase. Temperature distribution obtained by the transient thermal analysis was used in the calculations of the stresses on disc surface (Belhocine et al, 2014). Finite element method was used to calculate the heat generated on the surfaces of friction clutch and temperature distribution for case of bands contact between flywheel and clutch disc, and between the clutch disc and pressure plate (one bad central and two bands) and compared with case of full contact between surfaces for single engagement and repeated engagements (Abdullah et al, 2013). In other work, the finite element method used to study the contact pressure and stresses during the full engagement period of the clutches using different contact algorithms. Moreover, sensitivity study for the contact pressure was presented to indicate the importance of the contact stiffness between contact surfaces (Abdullah et al, 2013). The effect of sliding speed on contact pressure distribution, temperature and heat flux generated along the frictional surfaces was analyzed. A static structural analysis of the disc brake whose some composite materials were selected to compare the results obtained such as deflection and stresses (Sowjanya et al, 2013). Thermal and structural coupled analysis was carried out to find the strength of the disc brake in the research (Reddy et al, 2013).

\section{Materials and Methods}

\subsection{Materials used for the disc brake}

The Disc brake discs are commonly manufactured out of grey cast iron. The SAE maintains a specification for the manufacture of grey iron for various applications. For normal car and light truck applications, the SAE specification is J431 G3000 (superseded to G10). This specification dictates the correct range of hardness, chemical composition, tensile strength, and other properties necessary for the intended use. Some racing cars and airplanes use brakes with carbon fiber discs and carbon fiber pads to reduce weight. Wear rates tend to be high, and braking may be poor or grabby until the brake is hot. The materials used for rotor disc are explained in detail. It is investigating the temperature distribution, the thermal deformation, and the thermal stress of automotive brake disks have quite close relations with car safety; therefore, much research in this field has been performed.

\subsection{Modelling}

The disc brakes created using Solid works 2016 in which main modules are:
1) Sketcher
2) Part
3) Assembly

Sketcher is used to create design and part is used to apply extrude and material to see the model in ThreeDimensional as shown in Fig.1 and 2.

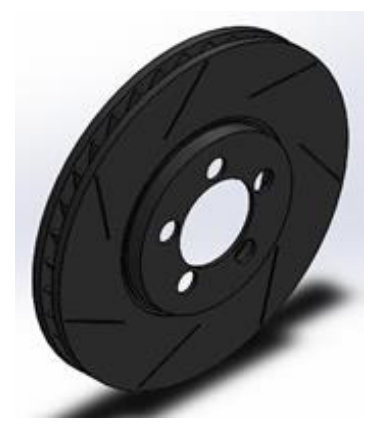

Fig.1 Slotted Disc Brake 
After Modelling of the disc brakes, the thermal analysis of the disc brakes are done in Ansys workbench 16.0.

\subsection{Thermal analysis}

For analysis the following assumption have been made Assumptions:

- Brake is applied on the front wheel only.

- The analysis is based on pure thermal loading. The analysis does not determine the life of the disc brake.

- The kinetic energy of the vehicle is lost through the brake discs i.e. no heat loss between the tyres and the road surface and the deceleration is uniform.

- The disc brake model used is of homogenous material.

- The thermal conductivity of the material used for the analysis is uniform throughout.

\section{Material properties}

NOTE: The specific heat of the material used is constant throughout and does not change with the temperature.

Material: Cast iron

Table 1 Cast iron Properties

\begin{tabular}{|c|c|c|c|}
\hline S.no & Property & Value & Units \\
\hline 1 & Density & 7200 & $\mathrm{Kgm}^{\wedge}-3$ \\
\hline 2 & Youngs Modulus & $1.1 \mathrm{E}+11$ & $\mathrm{~Pa}$ \\
\hline 3 & Poissions Ratio & 0.28 & $\mathrm{~Pa}$ \\
\hline 4 & Bulk Modulus & $8.3333 \mathrm{E}+10$ & $\mathrm{~Pa}$ \\
\hline 5 & Shear Modulus & $4.2969 \mathrm{E}+10$ & $\mathrm{~Pa}$ \\
\hline 6 & $\begin{array}{c}\text { Ultimate tensile } \\
\text { strength }\end{array}$ & $2.4 \mathrm{E}+08$ & $\mathrm{~Pa}$ \\
\hline 7 & $\begin{array}{c}\text { Ultimate compressive } \\
\text { strength }\end{array}$ & $8.2 \mathrm{E}+08$ & $\mathrm{Wm}^{\wedge}-1 \mathrm{C}^{\wedge}-$ \\
1
\end{tabular}

\section{Material: Stainless Steel}

Table 2 Stainless Steel Properties

\begin{tabular}{|c|c|c|c|}
\hline S.no & Property & Value & Units \\
\hline 1 & Density & 7750 & $\mathrm{Kgm}^{\wedge}-3$ \\
\hline 2 & Youngs Modulus & $1.93 \mathrm{E}+11$ & $\mathrm{~Pa}$ \\
\hline 3 & Poissions Ratio & 0.31 & $\mathrm{~Pa}$ \\
\hline 4 & Bulk Modulus & $1.693 \mathrm{E}+11$ & $\mathrm{~Pa}$ \\
\hline 5 & Shear Modulus & $7.3664 \mathrm{E}+10$ & $\mathrm{~Pa}$ \\
\hline 6 & $\begin{array}{c}\text { Tensile Yield } \\
\text { strength }\end{array}$ & $2.07 \mathrm{E}+08$ & $\mathrm{~Pa}$ \\
\hline 7 & $\begin{array}{c}\text { Compressive Yield } \\
\text { strength }\end{array}$ & $2.07 \mathrm{E}+08$ & $\mathrm{~Pa}$ \\
\hline 8 & $\begin{array}{c}\text { Tensile Ultimate } \\
\text { strength }\end{array}$ & $5.86 \mathrm{E}+08$ & $\mathrm{Wm}^{\wedge}-1 \mathrm{C}^{\wedge}-$ \\
1 \\
\hline 9
\end{tabular}

The goal of meshing in Workbench is to provide robust, easy to use meshing tools that will simplify the mesh generation process. The model using must be divided into a number of small pieces known as finite elements.
Since the model is divided into a number of discrete parts, in simple terms, a mathematical net or "mesh" is required to carry out a finite element analysis. A finite element mesh model generated is shown below with elements of 18768 and nodes of 33534.

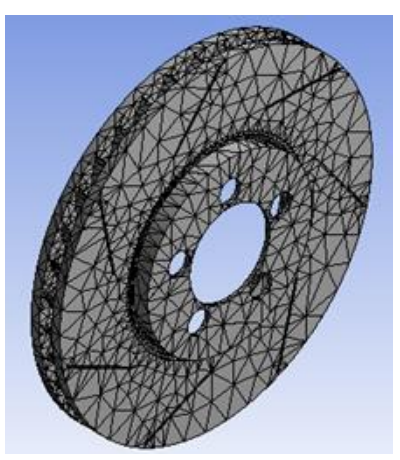

\section{Results and discussion}

The above figures showed that in slotted disc the redzones occur at the the edge of the rotor disc which is due to frictional force by the brake calliper. Since there is no drill holes in this type of design the convection of heat is less and hence the temperature is max compared to slotted and drilled disc brake. The maximum temperature for this disc is $947.4^{\circ} \mathrm{C}$ in using stainless steel as material and for cast iron it is 630.18 ${ }^{\circ} \mathrm{C}$

\subsection{Slotted disc brake using stainless steel}

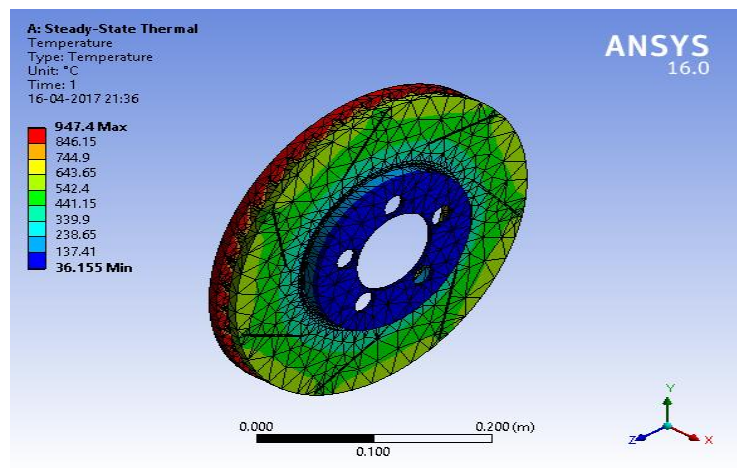

Fig.2 Nodal Temperature $\operatorname{Max}=947.4$, Min $=36.155$

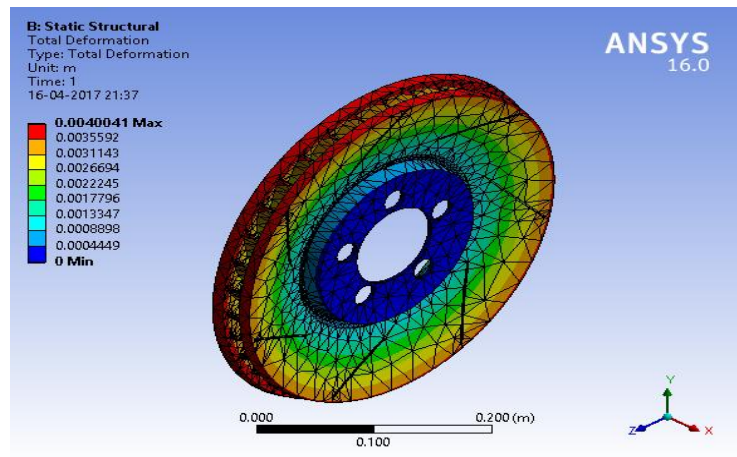

Fig.3 Total Deformation (in $\mathrm{m}$ ) $\operatorname{Max}=0.0040041$, Min $=0$ 


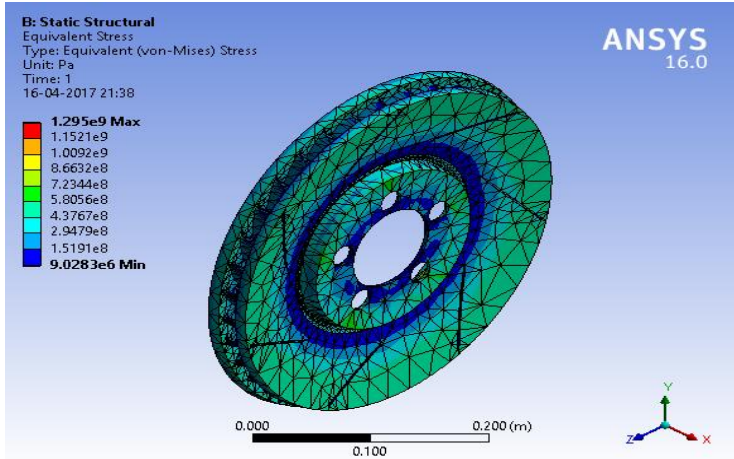

Fig.4 Equivalent Stress $\operatorname{Max}=1.295 \mathrm{e} 9, \mathrm{Min}=9.0283 \mathrm{e} 6$

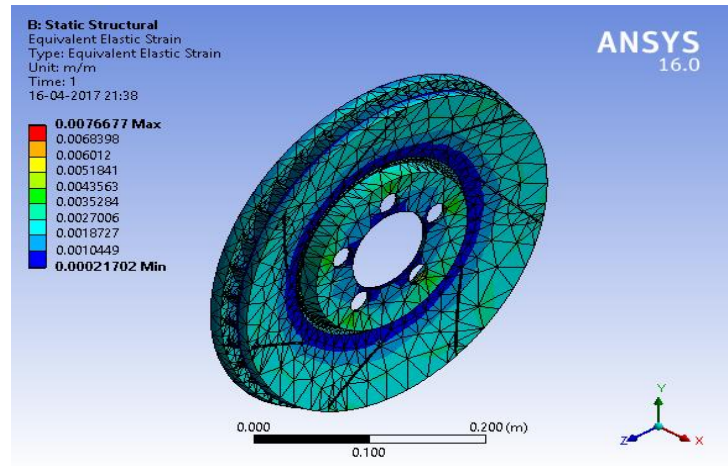

Fig.5 Equivalent Strain( in $\mathrm{m} / \mathrm{m}$ ) Max $=0.0076677$, Min $=0.00021702$

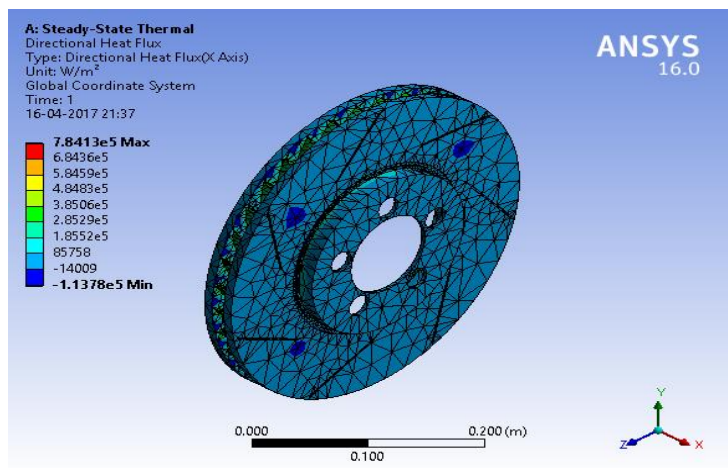

Fig.6 Heat Flux on ( $\mathrm{x}$-axis in $\mathrm{W} / \mathrm{m} 2)$ $\operatorname{Max}=7.8413 \mathrm{e} 5, \mathrm{Min}=-1.378 \mathrm{e} 5$

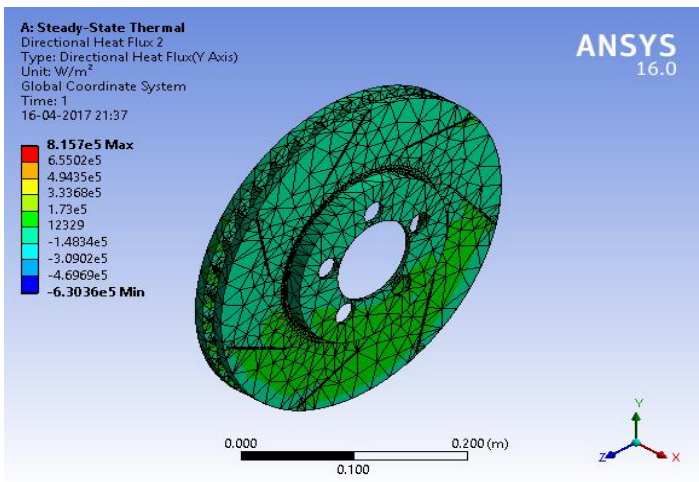

Fig.7 Heat Flux(Y -axis in $\mathrm{W} / \mathrm{m} 2)$ $\operatorname{Max}=8.157 \mathrm{e} 5, \mathrm{Min}=-6.3036 \mathrm{e} 5$

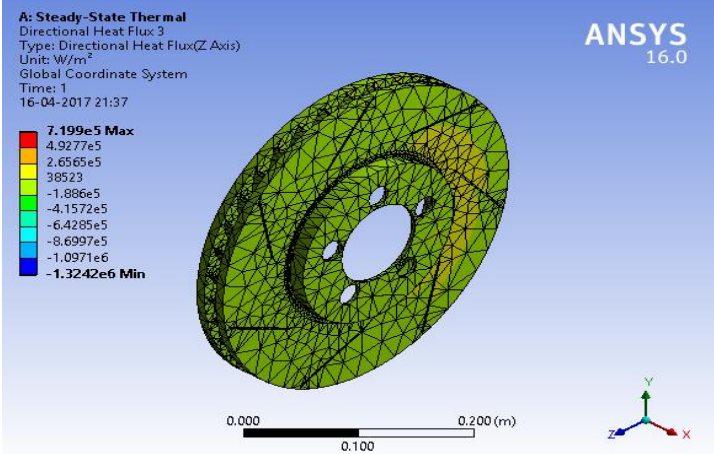

Fig.8 Heat Flux (z-axis in $\mathrm{W} / \mathrm{m} 2$ ) Max= 7.199e5, Min $=-1.3242 \mathrm{e} 6$.

4.2 Slotted disc brake using cast iron

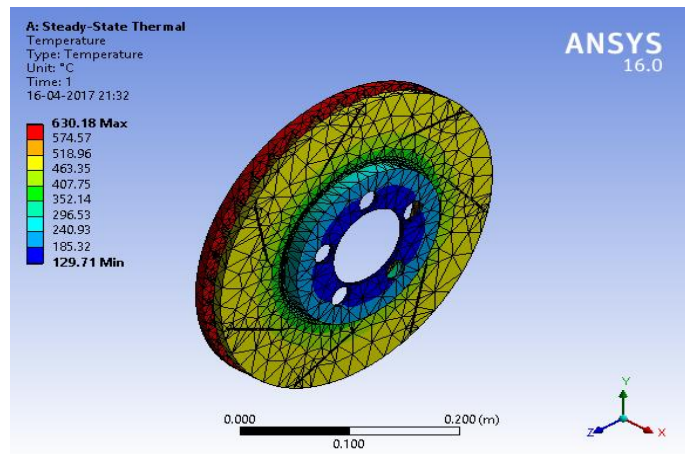

Fig.9 Steady State Thermal Temperature (in degrees) $\operatorname{Max}=630.18, \operatorname{Min}=129.71$

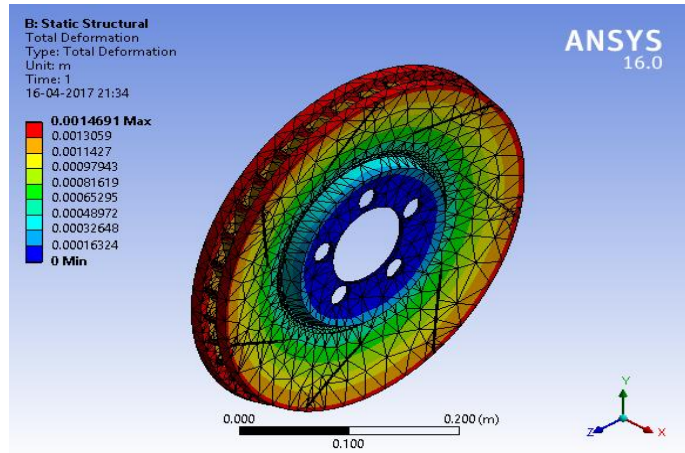

Fig.10 Total Deformation (in m) Max=0.0014691, Min $=0$

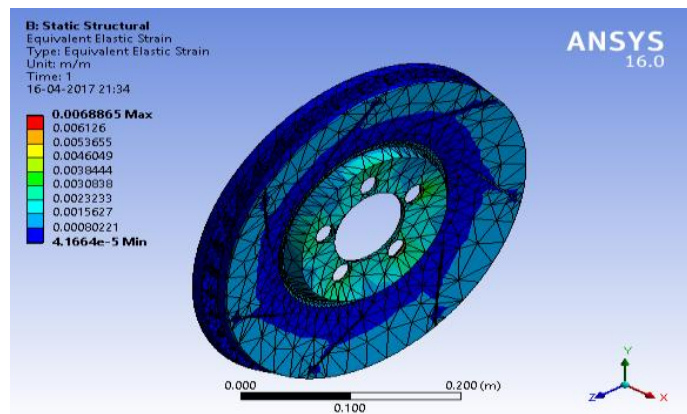

Fig.11 Equivalent Strain (in m/m) Max= 0.0068865, Min=0.00041664 


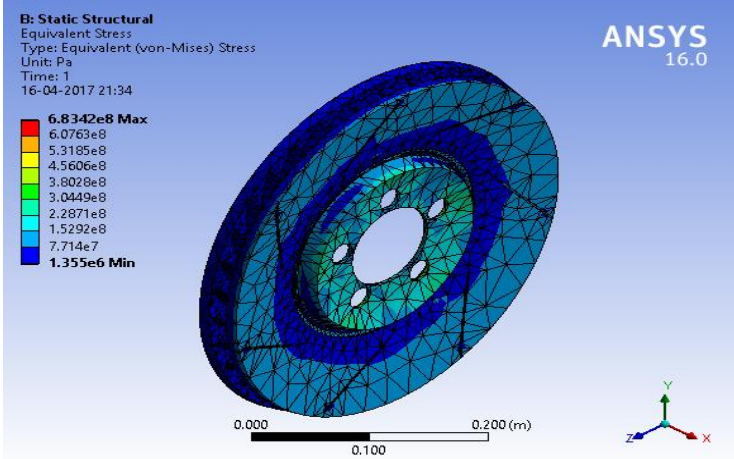

Fig.12 Equivalent Stress (von - mises in $\mathrm{Pa}$ ) $\operatorname{Max}=6.8 \mathrm{e} 8, \mathrm{Min}=1.33 \mathrm{e} 6$

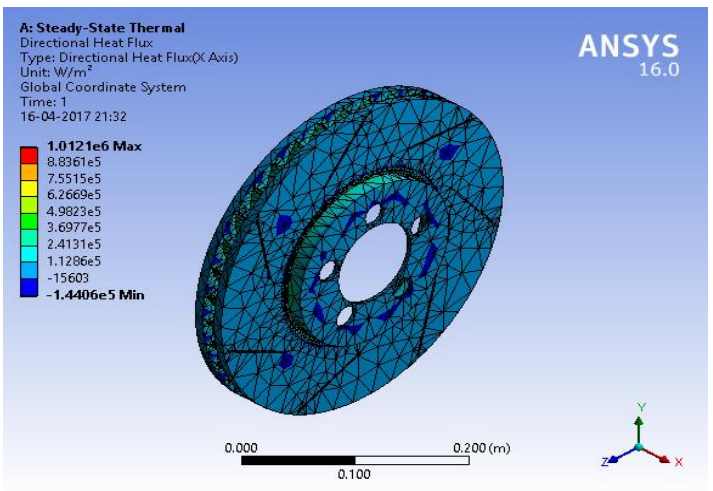

Fig.13 Heat Flux $(X$-axis in $\mathrm{W} / \mathrm{m} 2)$ $\operatorname{Max}=1.012 \mathrm{e} 6, \mathrm{Min}=-1.44 \mathrm{e} 5$

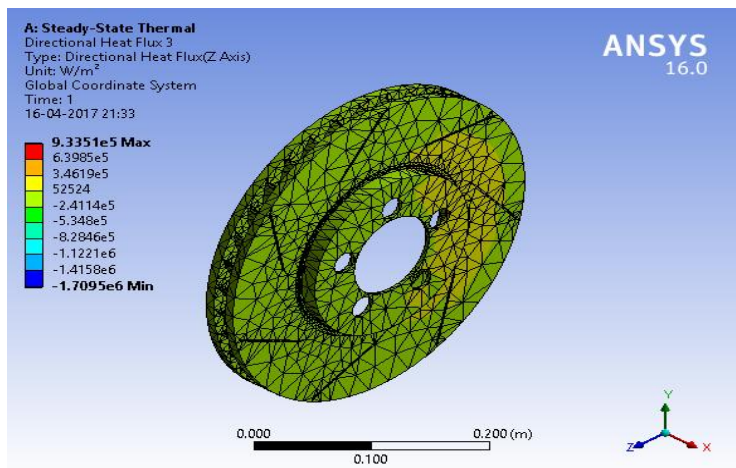

Fig.14 Heat Flux (Z -axis in $\mathrm{W} / \mathrm{m} 2)$ Max= 9.33e5, Min $=-1.709 \mathrm{e} 6$

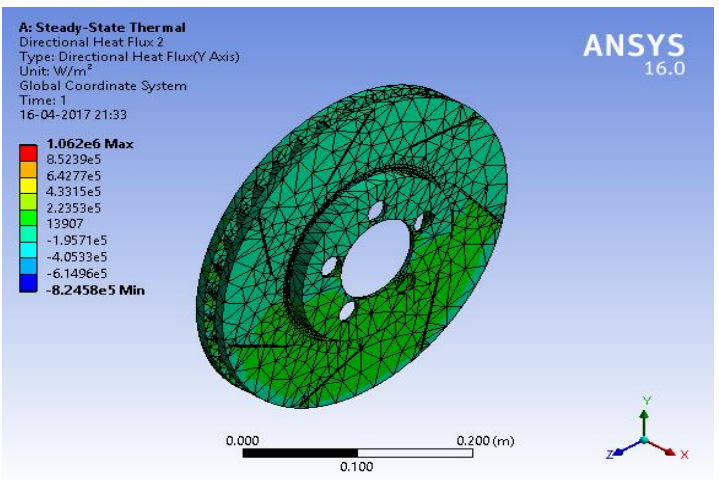

Fig.15 Heat Flux(Y -axis in $\mathrm{W} / \mathrm{m} 2)$ $\operatorname{Max}=1.062 \mathrm{e} 6, \mathrm{Min}=-8.24 \mathrm{e} 5$
Table 3 Comparison of CI and SS slotted disc

\begin{tabular}{|c|c|c|c|c|}
\hline \multirow{2}{*}{$\begin{array}{c}\text { Type Of } \\
\text { Material }\end{array}$} & \multicolumn{2}{|c|}{$\begin{array}{c}\text { Thermal } \\
\text { Temperature }\left({ }^{\circ} \mathrm{C}\right)\end{array}$} & \multicolumn{2}{c|}{$\begin{array}{c}\text { Thermal } \\
\text { Deformation(m) }\end{array}$} \\
\cline { 2 - 5 } & Max. & Min. & Max. & Min. \\
\hline Caste Iron & 630.18 & 129.17 & 0.0014691 & 0 \\
\hline $\begin{array}{c}\text { Stainless } \\
\text { Steel }\end{array}$ & 947.4 & 36.155 & 0.0040041 & 0 \\
\hline
\end{tabular}

\section{Conclusions}

Comparing the different results obtained from the analysis, it is concluded that Cast Iron is the best material for both slotted disc, because the thermal temperature and thermal stresses obtained for this material is lesser than compared to the stainless steel material.

- $\quad$ CI disc showed 33\% reduction in temperature

- Deformation was less in CI by $75 \%$ compared to SS

\section{References}

S. Lakkam, K. Suwantaroj, P. Puangcharoenchai, P. Mongkonlerdmanee, S. Koetniyom (2013) Study of heat transfer on front- and back-vented brake discs, Songklanakarin J. Sci. Technol. Vol. 35, No. 6, pp. 671681.

K. Lee (1999) Numerical Prediction of Brake Fluid Temperature Rise During Braking and Heat Soaking, The Soceity of Automotive Engineer Technical Paper, 1999-010483, pp. 1-9.

G. Cueva, A. Sinatora, W.L. Guesser, A.P. Tschiptschin (2013)Wear Resistance of Cast Irons used in Brake Disc rotors, Wear, Vol. 255, No. 7, pp. 1256-1260.

F. Bergman, M. Eriksson, S. Jacobson (1999) Influence of Disc Topography on Generation of Brake Squeal. Wear, Vol. 225-229, No. 1, pp. 621-628.

A. Papinniemia, C.S. Laia Joseph, J. Zhaob, L. Loader (2002)Brake squeal: a literature review, Applied Acoustics, Vol. 63, No. 4, pp. 391-400.

S. Koetniyom (2003) Temperature Analysis of Automotive Brake Discs, The Journal of King Mongkut's University of Technology North Bangkok, Vol. 13, pp. 36-42.

T. Kamnerdtong, S. Chutima, A. Siriwattanpolkul (2005) Analysis of Temperature Distribution on Brake Disc, in Proceeding of the 19th ME-NETT, October 19-21, Phuket, Thailand.

A. Belhocine, A.R. Abu Bakar, M. Bouchetara (2014)Numerical Modeling of Disc Brake System in Frictional Contact, Tribology in Industry, Vol. 36, No. 1, pp. 4966.

O.I. Abdullah, J. Schlattmann (2013) Effect of Band Contact on the Temperature Distribution for Dry Friction Clutch, Tribology in Industry, Vol. 35, No. 4, pp. 317329.

O.I. Abdullah, J. Schlattmann, A.M. Al Shabibi (2013) Stresses and Deformations Analysis of a Dry Friction Clutch System, Tribology in Industry, Vol. 35, No. 2, pp. 155162.

M.M.J. Akhtar, I.O. Abdullah, J. Schlattmann (2013) Transient Thermoelastic Analysis of Dry Clutch System, Machine Design, Vol. 5, No. 4, pp. 141- 150.

K. Sowjanya, S. Suresh (2013) Structural Analysis of Disc Brake Rotor, International Journal of Computer Trends and Technology (IJCTT), Vol. 4, No. 7, pp. 2295-2298.

V.C. Reddy, M.G. Reddy, G.H. Gowd (2013) Modeling And Analysis of FSAE Car Disc Brake Using FEM, International Journal of Emerging Technology and Advanced Engineering, Vol. 3, No. 9, pp. 383-389. 